\title{
PRODUÇÃO DE CACHAÇA ARTESANAL E SEU CONTEXTO: UM ESTUDO DE CASO COM ALAMBIQUES DO SUL DE MINAS GERAIS
}

Cassiano Nogueira Liz ${ }^{1}$; Roger Antônio Rodrigues ${ }^{1}$; Sheldon William Silva ${ }^{1}$; Antônio Carlos dos Santos $^{1} \&$ Tuane Ferreira Melo ${ }^{1}$

${ }^{1}$ Bacharel em Administração com linha de formação em Comércio Exterior pelo Centro Universitário do Sul de Minas - Varginha - MG

\section{RESUMO}

A presente pesquisa tem como principal objetivo demonstrar a importância da cachaça e sua participação no mercado. Busca identificar as etapas do seu processo produtivo e, a partir de um estudo de caso, analisar as principais estratégias utilizadas pelos produtores de cachaça artesanal e os principais desafios enfrentados nesse processo produtivo. Por meio de uma pesquisa bibliográfica e um estudo de caso realizado com três pequenos produtores de Cachaça Artesanal do Sul de Minas Gerais, pretende-se identificar os principais desafios de seu cotidiano. Diante do analisado perante os produtores, pode-se concluir que a maior dificuldade é realizar manobras que garantam os padrões de qualidade e identidade do produto, devido à falta ou prática ineficiente de métodos que eliminem as contaminações e comprometam o processo de fermentação, assim como utilizar os subprodutos.

Palavras-chave: Cachaça. Produção. Mercado 


\section{ABSTRACT}

This research aims to demonstrate the importance of cachaça and its market share. Seeks to identify the stages of the production process and from a case study, analyze the main strategies used by cachaça producers and the main challenges faced in this production process. Through a literature review and a case study of three small producers Artisanal Cachaça South of Minas Gerais, is intended to identify the main challenges of their daily lives. Before the analyzed before the producers, it can be concluded that the greatest difficulty is to perform maneuvers to ensure the quality and identity of the product standards due to the lack or inefficient practice methods that eliminate the contamination and compromise the fermentation process as well as using the byproducts.

Keywords: Cachaça. Production. Marketplace

\section{INTRODUÇÃO}

A Cachaça exerce importante papel econômico, social e cultural no Brasil. Sendo assim, é de fundamental importância que seus produtores possam agregar valor e qualidade à bebida sem abrir mão de competitividade e sustentabilidade. De acordo com dados do Centro Brasileiro de Referência da Cachaça (2012), a produção brasileira de cachaça no ano de 2012 foi estimada em 1,4 bilhões de litros, nível 15\% superior ao registrado no ano anterior. Nesse contexto, a cadeia produtiva movimentou R\$ 7 bilhões em fornecimento de insumos, produção e comercialização. De acordo com Cardoso et al (1999), o aumento do consumo de aguardente de qualidade e a possibilidade de exportação estão cada vez mais exigindo que o processo de fabricação de aguardente seja baseado em práticas criteriosamente determinadas para obtenção de um produto mais padronizado e com qualidade comprovada nos aspectos físico-químicos e sensoriais. A qualidade da aguardente requer conhecimentos científicos e tecnológicos apurados, competência, sensibilidade e dedicação (CARDOSO, 1999; COUTINHO, 2001; CHAVES, 2002; DANIEL, 2015). 
A presente pesquisa tem como principal objetivo demonstrar a importância da cachaça e sua participação no mercado. Busca identificar as etapas do seu processo produtivo e, a partir de um estudo de caso, analisar as principais estratégias utilizadas pelos produtores de cachaça artesanal e os principais desafios enfrentados nesse processo produtivo.

Como suporte teórico, o artigo apresenta o contexto da cachaça artesanal e sua relação com o mercado e as etapas de seu processo produtivo. A pesquisa privilegiou a abordagem qualitativa, utilizando-se fontes secundárias com análise documental para explorar a história e o contexto da cachaça artesanal. As fontes primárias privilegiaram três empresas da região sul de Minas Gerais, considerando o critério de acessibilidade. Os gestores dessas empresas foram entrevistados com o objetivo de analisar suas percepções com relação ao mercado da cachaça artesanal e as estratégias desenvolvidas por suas empresas.

A seguir, expõe-se um breve panorama da cachaça artesanal no Brasil, etapas do processo produtivo da cachaça e revisão de seus principais conceitos.

\section{REVISÃO BIBLIOGRÁFICA}

Este capítulo tem como objetivo apresentar o referencial teórico que sustenta o estudo proposto. Diante dessa proposição, faz-se necessário percorrer a literatura referente ao contexto que envolve a cachaça artesanal e seu setor, bem como sua evolução, estratégias e processo produtivo.

\section{CACHAÇA ARTESANAL: BREVE PANORAMA}

A bebida alcoólica tipicamente associada ao Brasil, conhecida por diversos nomes populares, como cachaça, aguardente, pinga, caninha, branquinha etc., possui dez variedades, segundo a legislação brasileira. A maior parte delas corresponde a atributos (adição de açúcar e tempo envelhecimento) imputados aos dois tipos básicos da bebida: a aguardente de cana e a cachaça. Segundo a Instrução Normativa 13, de 29 de junho de 2005, do Ministério da Agricultura, Pecuária e Abastecimento, a primeira é definida como a bebida com graduação alcoólica de $38 \%$ a $54 \%$, a 20 ㄷ C, obtida do destilado alcoólico simples de cana-de-açúcar ou pela destilação do mosto fermentado do caldo de cana-de-açúcar. A segunda é a denominação típica e exclusiva da aguardente de cana produzida no Brasil, com graduação alcoólica de $38 \%$ a $48 \%$, a 20 드, obtida 
pela destilação do mosto fermentado do caldo de cana-de-açúcar, com características sensoriais peculiares, podendo ser adicionada de açúcares até $6 \mathrm{~g} / \mathrm{l}$. Com vistas a simplificar a análise, 0 presente trabalho utilizará a denominação "cachaça” para representar as supracitadas variedades existentes (CERVIERI JÚNIOR, 2014).

De acordo com estimativas do Centro Brasileiro de Referência da Cachaça (2012), considerando a população entre 18 e 59 anos, o brasileiro consome em média, 11,5 litros de cachaça por ano. O consumo fica bem aquém se comparado a outras bebidas como a cerveja (média de 117 litros por brasileiro) e refrigerantes (média de 142 litros por brasileiro). No cenário mundial, a cachaça é o terceiro destilado mais consumido no mundo, atrás da vodca e do soju (bebida destilada originária da Coréia e feita de arroz), mas apenas em torno de $1 \%$ da produção nacional é exportada, sendo metade disto comercializada a granel.

Segundo Silva et al (2005), o agronegócio da cachaça vem atravessando um momento ímpar na sua história. As transformações ocorridas no setor nos últimos anos visando o aumento na qualidade da produção vêm ampliando o seu consumo e consolidando, assim, o fim do preconceito que persistiu sobre a bebida durante séculos. O agronegócio do setor movimentou

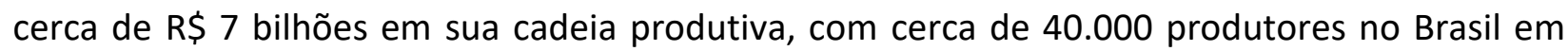
2012.

Nesse contexto, a produção de alcançada de 1,4 bilhões de litros se divide em $70 \%$ de cachaça industrial e $30 \%$ de cachaça de artesanal. O setor gera cerca de 600 mil empregos diretos e indiretos, sendo composto por cerca de 4.000 marcas de cachaça. De acordo com estimativas das entidades vinculadas ao processo produtivo da cachaça, o mercado informal ainda é elevado em algumas regiões e que, considerando sua produção, o volume de cachaça produzido aumentaria para algo em torno de 2 bilhões de litros/ano. A Figura 1 mostra a composição do setor de bebidas em relação ao valor das vendas e o volume produzido entre os anos de 2005 e 2011. 
Tabela 1: Composição do setor de bebidas, segundo valor das vendas e volume produzido - Brasil, acumulado 2005-2011 (em \%)

\begin{tabular}{|c|c|c|c|c|}
\hline \multirow[t]{3}{*}{ Segmento } & \multicolumn{4}{|c|}{ Participação } \\
\hline & \multicolumn{2}{|c|}{ Na classe } & \multicolumn{2}{|c|}{ No setor } \\
\hline & Valor & Volume & Valor & Volume \\
\hline $\begin{array}{l}\text { Aguardentes e outras } \\
\text { bebidas destiladas }\end{array}$ & 100,0 & 100,0 & 6,6 & 5,0 \\
\hline $\begin{array}{l}\text { Aguardente de cana- } \\
\text { de-açúcar (cachaça ou } \\
\text { caninha); rum ou tafiá }\end{array}$ & 48,8 & 79,0 & 3,2 & 3,9 \\
\hline $\begin{array}{l}\text { Bebidas alcoólicas } \\
\text { destiladas, de outros tipos } \\
\text { (aguardente de frutas, gim, } \\
\text { genebra etc.) }\end{array}$ & 24,8 & 10,6 & 1,6 & 0,5 \\
\hline Uisques & 11,2 & 1,7 & 0,3 & 0,1 \\
\hline Vodca & 10,7 & 6,3 & 0,7 & 0,3 \\
\hline $\begin{array}{l}\text { Aguardente de vinho ou de } \\
\text { bagaço de uva (conhaque, } \\
\text { brande etc.) }\end{array}$ & 4,5 & 2,5 & 0,7 & 0,1 \\
\hline
\end{tabular}

Fonte: IBGE - PIA-Produto.

No ambiente institucional o governo vem tentando reverter à situação com o decreto no 6871 de 04 de junho de 2009 que regulamenta em seu art. 53 trata do termo cachaça:

Art. 53. Cachaça é a denominação típica e exclusiva da aguardente de cana produzida no Brasil, com graduação alcoólica de trinta e oito a quarenta e oito por cento em volume, a vinte graus Celsius, obtida pela destilação do mosto fermentado do caldo de cana-de-açúcar com características sensoriais peculiares, podendo ser adicionada de açúcares até seis gramas por litro.

$\S 10$ A cachaça que contiver açúcares em quantidade superior a seis gramas por litro e inferior a trinta gramas por litro será denominada de cachaça adoçada.

$\S 20$ Será denominada de cachaça envelhecida a bebida que contiver, no mínimo, cinquenta por cento de aguardente de cana envelhecida por período não inferior a um ano, podendo ser adicionada de caramelo para a correção da cor. (BRASIL, Decreto Lei nำ6.871, 2009). 
De acordo com Reis Filho (2015), outra medida bastante requisitada pelos inúmeros produtores é a redução dos impostos, dentre eles o Imposto sobre Circulação de Mercadorias e Serviços (ICMS), de competência estadual. No Estado de Minas Gerais, um dos principais produtores da cachaça artesanal, há um projeto que visa reduzir a alíquota do ICMS de 18\% para 3\%. De acordo com a proposta, a redução da carga tributária diminuiria a informalidade e aumentaria a competitividade do setor.

Outro desafio do setor consiste em tornar a cachaça mais conhecida no mercado externo. Apenas 1\% da produção nacional é exportado, valor sobremaneira inferior ao de destilados associados a outros países. Segundo o Serviço Brasileiro de Apoio às Micro e Pequenas Empresas (Sebrae), o Brasil obtém receitas de pouco mais de US\$ 17 milhões com a exportação da cachaça. Para reverter esse quadro, é necessário tornar o produto desejável por classes superiores de renda, tanto no mercado interno como no externo. Para tal, é imprescindível regularizar a produção informal, ampliar os investimentos para divulgação do produto, valorizando sua brasilidade, além de investir na promoção das marcas e em design de embalagens (CERVIERI JÚNIOR, 2014). A seguir, apresenta-se as etapas do processo produtivo da cachaça, desde a etapa do plantio ao envase.

\section{PROCESSO PRODUTIVO DA CACHAÇA}

Antes de cultivar é necessário realizar um bom planejamento das atividades envolvidas, dentre elas a apreciação química da terra, onde seus resultados podem variar de acordo com a época, umidade e modo de coleta. Após a conclusão dos resultados e adotando-se devidas correções e adubações dentre elas a orgânica, pode-se obter boa produtividade. O planejamento norteará todo o processo produtivo para que o produtor possa eleger dentre as mais de 32 espécies conhecidas, optando em diferentes tipos de maturação, teor de sacarose, exigência de fertilidade do solo, brotação em soqueiras, bom perfilhamento, difícil tombamento, resistência a doenças, ausência de florescimento e fácil despalha (VITTI; MAZZA, 2002).

O plantio exige a correção do solo. Dentre os adubos utilizados, o orgânico disponível na região pode ser usado na cultura canavieira, barateando os custos de produção. Conforme Andrade (2004), o uso de estercos poderá até mesmo substituir a adubação química de plantio. Um dos 
fatores que regerá o processo de destilação é a escolha da maturação da cana, devendo optar por canas de ano-e-meio e cana de ano, respectivamente apresentadas nas Tabelas 1 e 2.

Tabela 1 - Período crescimento da cana de ano-e-meio.

\begin{tabular}{|c|c|c|c|c|c|c|c|c|c|c|c|c|c|c|c|c|c|}
\hline Jan & Fev & Mar & Abr & Mai & Jun & Jul & Ago & Set & Out & Nov & Dez & Jan & Fev & Mar & Abr & Mai & Jun \\
\hline \multicolumn{3}{|c|}{ Brota } & & & pous & & & & & $\begin{array}{r}\text { Cr } \\
\text { Veget }\end{array}$ & $\begin{array}{l}\text { scime } \\
\text { ativo I }\end{array}$ & $\begin{array}{l}\text { nto } \\
\text { htens }\end{array}$ & & & \multicolumn{3}{|c|}{ Maturação } \\
\hline
\end{tabular}

Fonte: Adaptado de ANDRADE, L.A. de B,. CARDOSO, M.B, 2004.

Tabela 2 - Período crescimento da cana de ano.

\begin{tabular}{|l|l|l|l|l|l|l|l|l|l|l|l|l|}
\hline Out & Nov & Dez & Jan & Fev & Mar & Mar & Abr & Mai & Jun & Jul & Ago & Set \\
\hline \multicolumn{3}{|l|}{ Brota } & \multicolumn{1}{l|}{ Vegetação } & \multicolumn{3}{l|}{ Maturação } \\
\hline
\end{tabular}

Fonte: Adaptado de ANDRADE, L.A. de B,. CARDOSO, M.B, 2004.

Antes de o produtor definir o período de produção cronológica deverá compor um mix de maturação da cana, conforme o período de produção, levando em consideração a existência de umidade no solo, temperaturas e demais condições climáticas (VITTI; MAZZA, 2002). Diversos fatores influenciam no bom desenvolvimento do canavial. Além das condições físicas e climáticas, a qualidade da mão de obra empregada no campo é um fator que merece destaque, juntamente com a oscilação do vento (ANDRADE, 2004).

De acordo com Andrade (2004), a colheita da cana-de-açúcar reflete todo o trabalho desenvolvido e conduzido no campo ao longo do ciclo da cultura, culminando na entrega da matéria prima para que a mesma seja processada e contribua na obtenção de um produto final de qualidade. Outrossim, muitos agricultores utilizam o processo de queima, visando a fácil despalha e consequente redução da mão de obra empregada. Vitti \& Mazza (2002) alertam que como efeito da queima, a formação de furfural e do hidrozimetilfurfural no próprio caldo da cana compromete a fermentação e a formação de um produto final de qualidade, visto que tais compostos são regulados a níveis aceitáveis.

O corte em grandes usinas de açúcar e etanol se dá através de maquinas que cortam as pontas da cana e picotam a corpo em pequenos pedaços ou ainda inteiros, mas em grande maioria dos 
produtores este processo ainda se dá de forma manual. Schoeninger et al (2014) destacam que a cana-de-açúcar deve ser processada em no máximo 24 horas após o corte, para que não ocorra diminuição da qualidade do produto a ser processado. A cana-de-açúcar para a produção de aguardente deverá estar limpa, com o menor teor de impurezas vegetais e minerais.

De acordo com Galdiano (2008), é importante que o produtor conheça o comportamento de cada variedade canavieira e o acúmulo de sacarose através da curva de maturação ou também conhecida como Índice de Maturação (IM) que se estabelece observando a relação brix do topo e o da base. Observando-se o índice de maturação pode-se estabelecer o PUI - Período Útil de Industrialização obtido através do refratômetro de brix que aponta valores que irão determinar o grau de maturação da cana (menor que 0,6 cana verde; 0,6 a 0,85 maturação média; de 0,85 a 1,0 cana madura) ou o uso do sacarímetro um equipamento simples (CRQ IV Região SP/MS). O momento ideal para a moagem é entre 16 e 18으 brix, mas dependendo da variedade canavieira pode chegar a ultrapassar $22 \circ$ brix. Quanto mais ultrapassar maior será o rendimento produtivo de álcool, entretanto, a concentração muito elevada de sacarose compromete a fermentação com formação de compostos secundários e fermentações incompletas, por outro lado o teor de sacarose reduzido contribui para fermentação mais rápida e maior multiplicação do pé de cuba, entretanto, causa redução do teor alcoólico, exigibilidade de maiores recursos produtivos e o maior consumo de água, vapor e facilidade de contaminação do mosto (CETEC, 08/2007).

Como forma de prevenir a contaminação do fermento e o maior rendimento das dornas é necessária à lavagem da cana visando retirar as impurezas como terra, micro-organismos e demais resíduos trazidos pela carreta (CRQ IV Região SP/MS). A cana recém-cortada que não exceda 24 horas devido à formação de alcoóis superiores deve ser armazenada em galpão com piso resistente e impermeável, coberto de maneira a proteger a cana dos efeitos negativos do sol e da chuva (AMPAQ, 2015).

O surgimento de diversos modelos de moendas proporciona ao produtor a maior extração do caldo, comumente orientado por engenheiros ou vendedores. A escolha da moenda adequada deve contemplar além da capacidade extração, o isolamento de óleos e graxas da área de operação, facilidade de higiene e limpeza após a operação diária, facilidade na aquisição de peças para reposição, assistência técnica (CRQ IV Região SP/MS). 
Após o processo de moagem o caldo deve cair em diversas peneiras de malhas finas e/ou tanques de decantação, visando à retirada de impurezas como terra, bagacilho e abelhas que são separadas do caldo, onde o equipamento deve possuir um design de fácil limpeza e higienização (AMPAQ, 2015).

Os tanques de filtragem, ajuste de brix, dornas de fermentação, tanques de expedição devem ser de inox, material inerte a composição do caldo, conforme exigências no Ministério da Agricultura (MAPA, 2016). Dessa forma, a fermentação é o passo mais importante na produção de uma Cachaça de Qualidade com aroma e sabor característicos e também o processo que exige maior rigidez e padronização (AMPAQ, 2015).

Para manter padrões de qualidade na fermentação e que ocorra sem a interferência de microorganismos, Ribeiro (2005) alerta para a necessidade de que os produtores adotem padrões rígidos de higiene, dentre eles a limpeza diária com água fervente ou vapor para esterilizar os canos, maquinários, esteiras, moendas, dornas e tanques e também fazer o uso de detergentes e desinfetantes aprovados para uso em indústria de alimentos, visando eliminar a atuação de micro-organismos.

A fermentação começa a ocorrer dias antes da produção da Cachaça com o processo de levantar o fermento. Com isso o produtor dispõe de diversas formulas passadas de pai para filho como o fermento artesanal composto de leveduras naturalmente presentes no meio ambiente como farelo de arroz, suco de limão ou laranja azeda e garapa e também há os fermentos químicos com leveduras selecionadas (AMPAQ, 2015).

Com isso se dá origem ao pé de cuba uma quantidade de 10 a $20 \%$ da capacidade da dorna onde após adicionado o caldo de cana passa-se a chamar vinho ou vinhoto iniciando o processo fermentativo que é dividido em duas etapas onde a primeira se caracteriza por ter de 14 a 18 o brix, multiplicação celular, produção de enzimas para a transformação de açucares em etanol, desprendimento de gás carbônico, aroma característico, aumento acentuado da temperatura e queda do brix (CRQ IV Região SP/MS).

A segunda etapa se dá quando ocorre o espelhamento do vinhoto, diminuindo a formação de bolhas, temperatura cai vagarosamente para a temperatura ambiente e estabilização do @Brix 
muito próximo à zero, momento este que o açúcar já foi consumido pelos organismos ali existentes devendo seguir para a fermentação (CRQ IV Região SP/MS).

A oscilação da qualidade ocorre com frequência devido a características assepsias e de temperatura que se fazem presentes e extremamente importantes desde o processo de colheita à conservação acarretando danos ao processo produtivo e consequentemente a qualidade do produto final. A contaminação afeta diretamente as leveduras que podem ser selecionadas ou não. As selecionadas possuem características pré-dispostas à resistência de determinadas culturas, porém, ambas as leveduras são afetadas com o frio onde temperaturas abaixo de 25ㅇ C diminuem a multiplicação, retardando o processo produtivo (CRQ IV Região SP/MS).

A destilação é a etapa responsável por separar todas as substancias de interesse formadas pela fermentação, por este motivo é um processo extremamente importante para a obtenção de uma cachaça de qualidade.

... além de ser feita de maneira artesanal, a Cachaça de Alambique não Contínuo, tem um outro grande "ingrediente" em sua composição: o alambique de cobre. Feita por um bom alambiqueiro, a Cachaça Artesanal feita neste equipamento é, segundo vários estudos, capaz de resultar em uma bebida mais fina e mais rica em sabores, aromas e cores: componentes sensoriais que fazem da Cachaça uma bebida com mais sabor. As cachaças destiladas em alambiques de cobre apresentaram teores de aldeídos e metanol superiores às cachaças destiladas em aço inox. Estudos acadêmicos comprovaram que os teores de dimetilsulfeto, alcoóis superiores e ésteres são maiores quando a destilação é feita em alambiques de aço inox. A utilização de aço inoxidável na construção de alambiques afeta as características sensoriais da aguardente, reduzindo a qualidade sensorial e produzindo um odor de enxofre desagradável no produto final. As reações químicas catalizadas pelo cobre nos alambiques, são capazes de reduzir significativamente os teores de dimetilsulfeto, o principal composto responsável pelo defeito sensorial das aguardentes de cana destiladas no inox (Mapa da Cachaça, 03/2011). 
Após o vinhoto entrar no alambique o mesmo é aquecido por vapor ou fornalha, onde o vapor pode ser controlado e a fornalha não. Este fator é muito importante, pois se a temperatura superar o ponto de ebulição o vinhoto ferve excessivamente não dando tempo de condensar e vem a cair nos canos de resfriamento, comprometendo a assepsia e não produzindo o destilado, este processo é conhecido como deixar o alambique 'vomitar'. Quando vinhoto chega à temperatura de ebulição entre 92,60 e 95,9 ํC há a evaporação do vinhoto dando origem ao destilado que se subdivide em cabeça, coração e cauda e a vinhaça, conforme exposto na Figura 3 (CRQ IV Região SP/MS).

Figura 3: Produtos do vinhoto.

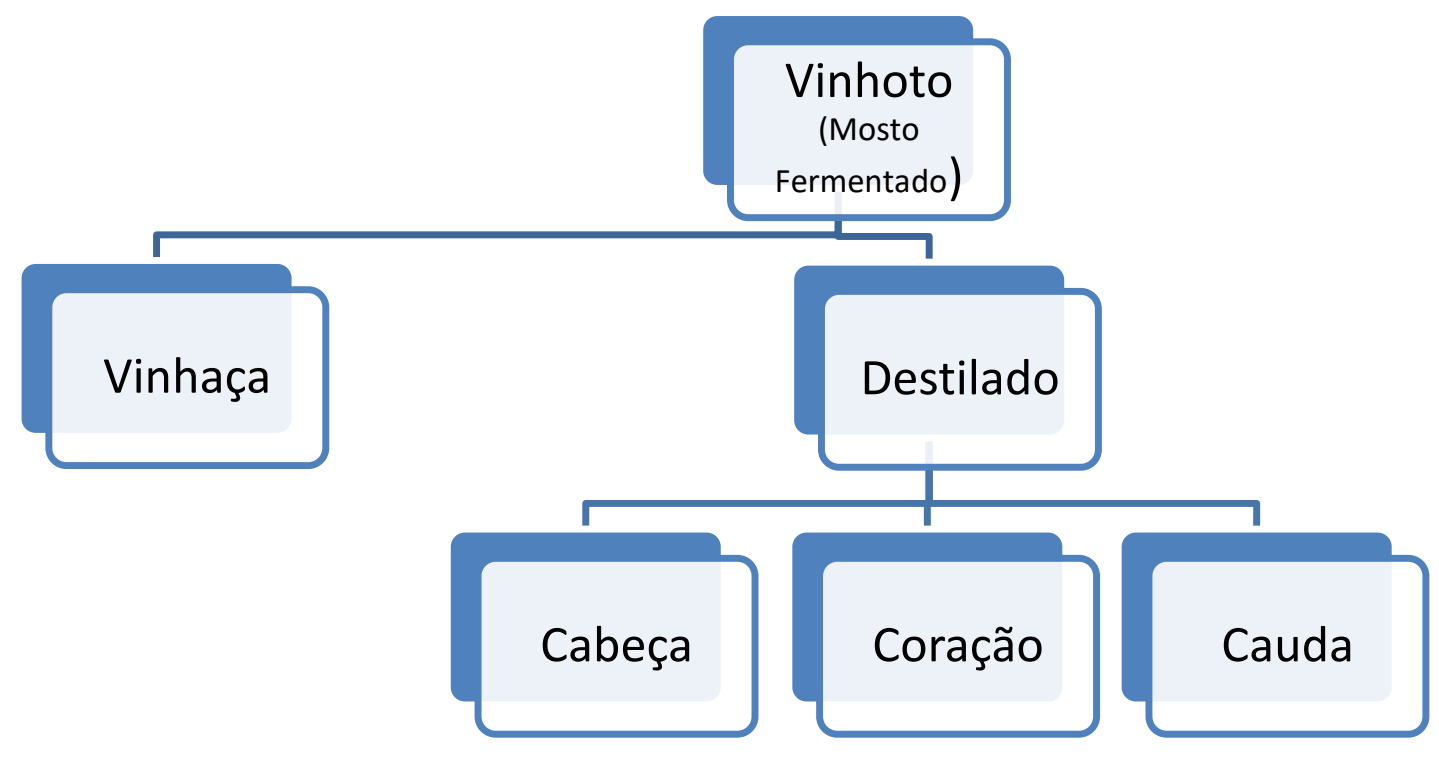

Fonte: Adaptado de ANDRADE, L.A. de B,. CARDOSO, M.B. 2004.

A vinhaça possui concentrações quase nulas de álcool e açucares há também substancias não voláteis do mosto, como nutrientes principalmente o potássio que é utilizado para a adubação da cultura como fertirrigação (CRQ IV Região SP/MS).

(...) No passado, foram inúmeros os episódios de poluição das águas causada pelo lançamento de efluentes líquidos nos corpos de água. A alta 
carga orgânica, associada à baixa vazão dos corpos receptores, provocou incontável mortandade de peixes. Nesta época, as águas de lavagem de cana e vinhaça eram lançadas nos rios (Mário. J.F.A, Maria K. D. 2007)

A vinhaça também é conhecida por vinhoto ou restilo esta despertando os olhares das grandes usinas e também dos produtores de Cachaça devido aos seus nutrientes, principalmente o potássio que pode ser utilizado para a adubação de pastos e do próprio canavial onde se permite a total reciclagem dos resíduos industriais como também a água de lavagem da cana e a limpeza do chão. A fertirrigação vem se tornando comum graças aos seus benefícios, porém para tal prática são necessários alguns cuidados como as doses depositadas em cada $\mathrm{m}^{3}$ por hectare e principalmente com os mananciais se fazendo necessário a atuando a fiscalização e controle para tornar esta medida sustentável e renovável (Mário. J.F.A, Maria K. D. 2007).

O destilado se subdivide em três produtos: a cabeça com graduação maior de 60 GL com compostos inorgânicos como etanol, metanol, acetaldeído, acetato de etila e metila, coloração forte; o coração com graduação entre 38 a 60 GL coloração límpida com aroma e sabor típicos da cachaça; e a cauda, com 10 a 38o GL possuindo compostos fenólicos e ácidos orgânicos com sabor e aroma muito fraco de cachaça (FURBINO, 2013).

A temperatura dentro do alambique influencia diretamente nos compostos presentes na cachaça onde diversos componentes podem ser liberados graças ao excesso de temperatura. Deste modo o alambiqueiro deve policiar o tempo todo à temperatura interna do alambique a fim de não colocar em ebulição compostos indesejáveis e dosar a quantidade de compostos como a água vista que a ebulição do vinhoto ocorre entre 92,60 e 95,9 ㄷ (CRQ IV Região SP/MS).

Após ebulição do vinhoto os vapores são resfriados na coluna do alambique onde contém um desfragmentador preenchido no seu interior por água fria corrente, possibilitando a condensação e posterior queda dos líquidos na serpentina que por sua vez esta envolvida em água fria que terminará em um tanque para separação dos produtos derivados da destilação. 


\section{MATERIAIS E MÉTODOS}

O objetivo principal desta pesquisa é demonstrar a importância da cachaça e sua participação no mercado, identificando as etapas do seu processo produtivo.

Com relação aos fins, a pesquisa é descritiva, levando-se em consideração o fato de que a mesma pretende obter e investigar o contexto em que se ocorre a produção de cachaça artesanal (Gil, 2002; Raupp \& Beuren, 2003; Vergara, 2003). Quanto aos meios, a presente pesquisa é documental e empírica. De acordo com Richardson (1999, p.85) o pesquisador pode utilizar "como material de estudo qualquer forma de comunicação, usualmente documentos escritos, como livros, periódicos, jornais, mas também, pode recorrer a outras formas de comunicação". Quanto à abordagem, a pesquisa é qualitativa. De acordo com Neves (1996, p.104), a pesquisa qualitativa visa "obter dados descritivos mediante contato direto e interativo do pesquisador com a situação objeto do estudo". Ainda de acordo com o autor, nas pesquisas qualitativas "é frequente que o pesquisador procure entender os fenômenos, segundo a perspectiva dos participantes da situação estudada e, a partir daí, situe sua interpretação dos fenômenos estudados".

Este trabalho ainda assume a característica de um estudo de caso. De acordo com Yin (2001, p.26) o estudo de caso é escolhido "ao se examinarem acontecimentos contemporâneos, mas quando não se podem manipular comportamentos relevantes". Segundo Gil (2002, p.54) o estudo de caso consiste no "estudo profundo e exaustivo de um ou de poucos objetos, de maneira a permitir o seu conhecimento amplo e detalhado".

Essa pesquisa utilizou como caso três alambiques devidamente registrados, produtores de cachaça artesanal, localizados na região sul de Minas Gerais. As empresas foram selecionadas de acordo com o critério de acessibilidade. Visando a manutenção do sigilo das empresas pesquisadas, nomearemos de Alambique A, Alambique B e Alambique C.

A entrevista semiestruturada foi a técnica utilizada com a finalidade de investigar o contexto da cachaça artesanal, sua relação com o mercado e as etapas de seu processo produtivo. De acordo com Boni e Quaresma (2005, p.75), as entrevistas semiestruturadas combinam "perguntas abertas e fechadas, onde o informante tem a possibilidade de discorrer sobre o tema proposto". A pesquisa foi desenvolvida junto aos gestores das empresas pesquisadas, de maneira a permitir 
um diagnóstico da percepção dos respondentes em relação ao mercado da cachaça artesanal e as estratégias desenvolvidas por suas empresas.

Foram realizados três contatos com os respondentes que resultaram nas entrevistas gravadas, que foram transcritas e analisadas sob a técnica de análise de conteúdo nos termos de Bardin (1997). A análise de conteúdo, de acordo com Bardin (1997, p.31) "é um conjunto de técnicas de análise das comunicações". O autor ainda completa: "não se trata de um instrumento, mas de um leque de apetrechos marcado por uma grande disparidade de formas e adaptável a um campo de aplicação muito vasto". Minayo $(1999$, p.74) destaca duas funções na aplicação dessa técnica: a verificação de hipóteses ou questões e a descoberta do que está por trás dos conteúdos manifestos, indo além das aparências do que está sendo comunicado.

\section{RESULTADOS E DISCUSSÕES}

A partir deste conjunto de informações e das entrevistas realizadas, será apresentado um cruzamento entre as informações obtidas por meio da pesquisa realizada com os gestores. Um ponto comum identificado na entrevista com os gestores foi a percepção que detêm do mercado. Os entrevistados concordam que o mercado está cada vez mais receptivo ao produto. Mesmo assim, alertam para a informalidade de alguns alambiques, que fomentam uma concorrência desleal e acirra a disputa no setor. Os respondentes ainda argumentam que há uma grande dificuldade em manter padrões de qualidade e identidade do produto final comercializado, estando assim a mercê de grandes oscilações de compras e serem 'obrigados' a investir constantemente na fidelização de seus clientes.

Eu percebo fortemente que nós, pequenos produtores, temos dificuldades em realizar ações comerciais para mudar a percepção do consumidor diante de produtos substitutos como a Vodca, Tequila, Rum, Whisky; e, principalmente em relação a cachaça industrializada (Gestor do Alambique 3).

O fator negativo mais atuante presente nas empresas pesquisadas é a dificuldade do produtor e seus colaboradores em compreender a grande necessidade de obter um alto padrão de qualidade 
na admissão da matéria prima e na regular esterilização dos equipamentos. Devido à alta rotatividade de mão obra, os custos de produção aumentam devido a necessidade de proporcionar treinamento e capacitação dos colaboradores. Tal afirmação pode ser identificada na fala do gestor do Alambique 2

... o funcionário chega e não sabe operar os equipamentos. Muitos deles desconhecem a sua interação com o produto final. Diante da dificuldade de encontrar mão-de-obra treinada, que, que possuo conhecimentos avançados no plantio devido minha formação acadêmica, não penso em expandir meu mercado, estrutura física, etc. Eu não exploro todo o meu potencial. É uma opção que fiz, diante das dificuldades que encontro com mão-de-obra (Gestor do Alambique 2).

Um dos pontos destacado nas etapas do processo produtivo da cachaça artesanal foi a colheita da cana-de-açúcar. Soratto et al (2007) atenta para o fato de que a colheita pode ser mecanizada ou manual, sem a queima da palha do canavial para preservar as características naturais da planta, melhorando o processo de fermentação natural do caldo. O processo de mecanização, de acordo com relato do Gestor do Alambique 3, reduz drasticamente o custo de produção da cachaça artesanal, gerando renda a partir de outros subprodutos.

... bem, eu consigo empregar intensamente métodos, equipamentos adaptados que reduzem drasticamente o custo de produção e também utiliza de diversos subprodutos do processo produtivo, como o álcool combustível, alimentação de gado, cultivo de cogumelos, venda da palha da cana compactada como lenha (Gestor do Alambique 3).

Mediante a pesquisa realizada, outro ponto que merece destaque é a necessidade de obter melhorias, principalmente higiênicas. O relato do Gestor do Alambique 1 mostra sua dificuldade em obter a máxima qualidade no processo de higienização

No meu processo de fabricação, eu não consigo exercer regularmente a esterilização dos equipamentos e limpeza da 
matéria prima totalmente. Nesse momento, corro o risco de cometer falhas e contaminações, o que pode gerar um prejuízo muito grande. (Gestor do Alambique 3).

\section{CONSIDERAÇÕES FINAIS}

A partir dessa investigação, conclui-se que a produção de cachaça artesanal possui extrema importância econômico-social. Além da importância cultural na qual seus elementos e história estão vinculados, o setor ampliou sua produção, oportunizou a entrada de novos produtores e ofereceu uma quantidade significativa de empregos. Sendo assim, a cachaça artesanal se consolidou como um produto certificado e genuinamente brasileiro (CARDOSO et al, 1999; DE OLIVEIRA \& RIBEIRO, 2002; BARBOZA \& FARIA, 2015).

A percepção dos respondentes em relação ao setor, mesmo tendo sido unanimes ao considerar a receptividade do mercado em relação à cachaça artesanal, expressa pessimismo. Os produtores relatam dificuldades em manter a qualidade do processo produtivo. A situação é preocupante considerando que os respondentes evidenciaram sérios problemas associados à manutenção de mão-de-obra qualificada e a completa higienização no decorrer do processo de fabricação. Esses achados corroboram para que o produtor minimize suas ações comerciais e não eleve sua capacidade produtiva. Outras pesquisas realizadas também atestam essa conclusão, conforme pesquisas realizadas por Coutinho (2003), Espinoza e Botelho (2006) Coutinho et al (2015), Schoeninger (2014) e Oliveira (2016).

Cabe ainda ressaltar que o presente estudo apresenta limitações em relação aos dados coletados. As informações mais recentes de entidades e associações de pesquisa e promoção da cachaça artesanal encontradas datam de 2012. Nesse sentido, não é possível identificar o atual panorama do setor. Essa limitação interfere no confronto das informações obtidas no referencial teórico e as entrevistas realizadas. Enquanto a literatura expressa as potencialidades do setor, os produtores estão pessimistas em relação ao cenário atual. Outra limitação a ser apontada é o fato de que a produção de cachaça artesanal incorpora outros elementos que não foram descritos, como o processo de envelhecimento e a utilização de madeiras, a clandestinidade e informalidade no setor e o aproveitamento dos resíduos da produção. Essas limitações conferem a 
oportunidade de novos estudos, tendo em vista investigar e minimizar as limitações encontradas nessa pesquisa.

\section{REFERÊNCIAS BIBLIOGRÁFICAS}

AMPAQ. Disponível em: <http://www.ampaq.com.br.>. Acesso em: 01 set. 2015.

Andrade, L.A. de B.; Cardoso, M.B. Cultura da cana de açúcar. Lavras: UFLA/FAEPE, 2004.

Barboza, R. A.; Faria, J. B. Inovação em pequena empresa: um estudo com produtores de cachaça. Revista Ciência em Extensão, v. 11, n. 2, p. 38-55, 2015.

Bardin, L. (1997). Análise de conteúdo. Lisboa: Edições 70.

Boni, V. Quaresma, S. J. (2005). Aprendendo a entrevistar: como fazer entrevistas em Ciências Sociais. Revista Eletrônica dos Pós-Graduandos em Sociologia Política da UFSC, v. 2, n. 1, p. 6880.

BRASIL. Lei no 6.871, de 4 de junho de 2009 (Decreto/Lei regulamentadora da padronização, classificação, registro, inspeção e fiscalização da produção e do comércio de Cachaças). Disponível em: <http://www.planalto.gov.br/ccivil_03/_Ato2007-2010/2009/Decreto/D6871.htm >. Acesso em: 01 jun. 2015.

BRASIL. Instrução Normativa no 13 do Ministério da Agricultura, Pecuária e Abastecimento, de 29 de junho de 2005 (Regulamento Técnico para Fixação dos Padrões de Identidade e Qualidade para Aguardente de Cana e para a Cachaça). Disponível em: <http://extranet.agricultura.gov.br/sislegisconsulta/consultarLegislacao.do?operacao=visualizar\&id=12386>. Acesso em: 01 jun. 2015.

Cardoso, M. G., Campos, G. A., Silva, R. A., Santos, C. D., Pinto, A. P. S., \& Silva, C. F. (1999). Cachaça: qualidade e produção. Extensão. Bol. Técn. Sér Série, 8, 1-26.

CENTRO BRASILEIRO DE REFERENCIA DA CACHAÇA. (2012). Números da Cachaça. Disponível em http://www.expocachaca.com.br/bh/numeros-da-cachaca.shtml. Acesso em 02/04/2016. 
Cervieri Júnior, O., Júnior, T., Rodrigues, J., Galinari, R., Rawet, E. L., \& Silveira, C. T. J. D. (2014). O setor de bebidas no Brasil. BNDES Setorial, Rio de Janeiro, (40).

Chaves, J. (2002). Cachaça: produção artesanal de qualidade. Cachaça: produção artesanal de qualidade.

Coutinho, E. P. (2001). Dinâmica da modernização do setor de produção de aguardente de canade-açúcar no Brasil: construindo uma cachaça de qualidade. 2001 (Doctoral dissertation, Tese (Doutorado em Engenharia da Produção)-Universidade Federal do Rio de Janeiro, Rio de Janeiro). Coutinho, E. P. (2003). Práticas ultrapassadas e mitos de qualidade na cadeia de produção de cachaça artesanal. Anais do 23ํㅡㄹ ENEGE, Ouro Preto-MG.

Coutinho, E. P., Ramos, Z. N. S., dos Santos Alves, A., \& da Silva Oliveira, R. E. (2015). Boas Práticas de Fabricação de Cachaça de Alambique: Visão Técnica Versus Empresarial. UNOPAR Científica Ciências Biológicas e da Saúde= Journal of Health Sciences, 14(3).

CRQ IV Região SP/MS. Tecnologia de Produção da cachaça. Disponível em http://www.crq4.org.br/downloads/tec cachaca.pdf. Acesso em 02/04/2016.

Daniel, R. C. (2015). Alambiques e pequena produção no interior paulista: informalidade como identidade e preservação do modo de vida dos produtores frente às demandas do mercado. Revista Espaço de Diálogo e Desconexão, 8(2).

De Oliveira, Elias Rodrigues; Ribeiro, Eduardo Magalhães. Indústria Rural, Agricultura Familiar e Desenvolvimento Local: O Caso da Produção de Cachaça Artesanal em Salinas-Minas Gerais. Centro, v. 551, n. 54, p. 14, 2002.

Espinosa, L.J.S,. Botelho, M.S.; Botelho, M.S.; Boas praticas de fabricação para estabelecimentos produtores de Cachaça: Aspectos higiênico-sanitárias. Lavras: UFLA/FAEPE, 2006. 
Furbino, Z. Pequenos agricultores mineiros fabricam etanol para abastecer veículos próprios. Out de 2013. Disponível em: <http://www.em.com.br/app/noticia/economia/2013/10/27/internas_economia,464219/pequ enos-agricultores-mineiros-fabricam-etanol-para-abastecer-veiculos-proprios.shtml>. Acesso: 01 de junho de 2015.

Galdiano, L. C. Qualidade da cana-de-açúcar (Saccharum spp) submetida à aplicação de maturadores químicos em final de safra. Jaboticabal: UNESP, 2008. 53 f. Dissertação de mestrado. Gil, A. C. (2002). Como elaborar projetos de pesquisa. São Paulo: Atlas.

Mário, J. F.A, Kátia, M. D. - Impactos Ambientais da Agroindústria da Cana de Açúcar: Subsidios para a Gestão, Set/2007. Piracicaba - SP. Disponível em: <http://www.ambiente.sp.gov.br/wpcontent/uploads/publicacoes/etanol/impactosAmbientaisAgroindustria.pdf>. Acessado em 01 de Junho de 2015.

MAPA DA CACHAÇA. Diferenças entre Cachaça Artesanal e Cachaça Industrial. Mai de 2011. Disponível em: < http://www.mapadacachaca.com.br/artigos/diferencas-entre-cachacaartesanal-e-cachaca-industrial/ >. Acesso em: 01 de junho de 2015.

Minayo, M. C. de S. (1999) Pesquisa Social: teoria, método e criatividade. Petrópolis: Vozes. Neves, J. L. (1996). Pesquisa qualitativa: características, usos e possibilidades. Cadernos de pesquisas em administração, São Paulo, v. 1, n. 3, p. 103-113.

Oliveira, Leonardo Monteiro de Barros. Inovação em um produto típico: a cachaça artesanal certificada de Minas Gerais. 2016.

Raupp, F. M. Beuren, I. M. (2003). Metodologia da pesquisa aplicável às ciências sociais. São Paulo: Atlas.

Richardson, R. J. (1999). Pesquisa social: métodos e técnicas. São Paulo: Atlas. 
SEBRAE/IBRAC. Boletim Informativo, de 2014 (Potencial da Cachaça). Disponível em: <http://www.sebrae2014.com.br/Sebrae/Sebrae\%202014/Boletins/2014_02_04_BO_Outubro_ Agronegocio_Cachaca_pdf.pdf>. Acesso em 01 de junho de 2015.

Silva, L., Rocha, L., Lima, I., \& Santos, G. (2005). Cachaça de Minas" e desenvolvimento rural: uma análise do cooperativismo como impulso para o agronegócio.

Vergara, S. C. (2003). Projetos e relatórios de pesquisa em administração. São Paulo: Atlas.

Vitti, G.C., Mazza, J.A. Planejamento, estratégias de manejo e nutrição da cultura de cana-deaçúcar. Piracicaba: POTAFOS, 2002. 16p. (Encarte técnico / Informações Agronômicas).

Yin, R. K. (2001). Estudo de caso - planejamento e métodos. São Paulo: Bookman. 